\title{
Concepções de estudantes sobre a maturidade para a escolha da graduação em Psicologia
}

\section{Concepts of students on maturity for the choice of graduation in Psychology}

\section{Concepciones de estudiantes sobre la madurez para la elección de la graduación en Psicología}

\section{Adriana Benevides Soares*}

Universidade Salgado de Oliveira - Universo, Niterói, Rio de Janeiro, Brasil

\section{Marisangela Siqueira de Souza**}

Universidade Salgado de Oliveira - Universo, Niterói, Rio de Janeiro, Brasil

Marcia Cristina Monteiro***

Universidade Salgado de Oliveira - Universo, Niterói, Rio de Janeiro, Brasil

\section{Rafael Moura Coelho Pecly Wolter****}

Universidade Federal do Espírito Santo - UFES, Vitória, Espírito Santo, Brasil

\begin{abstract}
RESUMO
O aumento da oferta e da procura por cursos de Psicologia tem despertado pesquisas para compreender o processo de escolha da carreira e da qualidade da formação no exercício da profissão. O objetivo foi identificar as concepções espontâneas do conceito de maturidade psicológica para a escolha da profissão para os estudantes de Psicologia. Participaram 13 estudantes de uma instituição particular, de ambos os sexos, idade entre 20 e 48 anos $(M=32,15 \% ; D P=9,54)$ e de classes sociais diversas. Os períodos foram um $(7,7 \%)$ participante do primeiro, três $(23,1 \%)$ do segundo, um $(7,7 \%)$ do terceiro e quinto respectivamente, três $(23,1 \%)$ do sexto, um $(7,7 \%)$ do sétimo e dois $(15,4 \%)$ do oitavo. 0 estudo é exploratório, qualitativo e utilizou a metodologia de Grupo Focal. Utilizou-se o software Iramuteq 0.7 para análise dos dados que apontaram para cinco classes gerais. A pesquisa mostrou que a concepção para a escolha do curso de Psicologia tem relação com as características e habilidades autopercebidas e deverão ser desenvolvidas ao longo da graduação. 0 estudo buscou colaborar com o entendimento do perfil do estudante de psicologia no Brasil e na melhora do processo de formação desses profissionais.
\end{abstract}

Palavras-chave: maturidade psicológica, universitários, psicologia, escolha da carreira, grupo focal. 


\begin{abstract}
The increase of offering and demand for Psychology courses has stimulated researches to understand the process of career choice and how this can affect the quality of their formation and their profession performance. The study aims to identify the spontaneous conceptions of psychological maturity to the career choice for Psychology students. The participants of this research were thirteen students from a private Higher Education institution of both sexes, aged between 20 and 48 years $(M=32.15 \%, S D=9.54)$ and from different socioeconomic classes. The periods were: one participant $(7.7 \%)$ from the first period; three $(23.1 \%)$ from the second; one $(7.7 \%)$ from the third and fifth respectively; three $(23.1 \%)$ from the sixth; one $(7.7 \%)$ from the seventh and two (15.4\%) from the eighth. The study was exploratory, qualitative and used the Focal Group methodology. The I ramuteq 0.7 software was used to data analysis that pointed to five general classes. The results indicate that the conception for the psychology course choice is related to the characteristics or abilities perceived by the students and should be developed during the graduation process. This study collaborated to understand the Psychology student profile in Brazil, as well, with the improvement of the formation process of these professionals.
\end{abstract}

Keywords: psychological maturity, university students, psychology, career choice, focus group.

\title{
RESUMEN
}

El aumento de la oferta y la demanda por carreras de Psicología ha motivado investigaciones para comprender el proceso de elección de la carrera y de la calidad de la formación en el ejercicio de la profesión. El estudio tiene como objetivo identificar las concepciones espontáneas de madurez psicológica para la selección de la profesión para los estudiantes de Psicología. Participaron 13 estudiantes, de ambos sexos, entre 20 y 48 años ( $\mathrm{M}=$ $32,15 \%$, DP $=9,54)$ y de clases sociales diversas. Los períodos fueron un $(7,7 \%)$ participante del primero, tres $(23,1 \%)$ del segundo, uno $(7,7 \%)$ del tercero y quinto respectivamente, tres $(23,1 \%)$ del sexto, uno $(7,7 \%)$ del séptimo y dos $(15,4 \%)$ del octavo. El estudio es exploratorio, cualitativo y utilizó la metodología de Grupo Focal. Se utilizó el software Iramuteq 0.7 para el análisis de los datos que apuntaron a cinco clases generales. La investigación demostró que la concepción para la elección de la carrera de Psicología se relaciona con las características y habilidades auto-percibidas y deberán ser desarrolladas durante la graduación. El estudio buscó colaborar con la comprensión del perfil del estudiante de psicología en Brasil y en la mejora del proceso de formación de esos profesionales.

Palabras clave: madurez psicológica, universitarios, psicología, elección de la carrera, grupo focal.

\section{I ntrodução}

O momento de escolha profissional é um período de grande ansiedade para alguns indivíduos, especialmente para os jovens, que são demandados a apresentar certo nível de maturidade para a tomada de decisão quanto ao seu futuro profissional. Apesar da escolha profissional ser uma decisão complexa, para o adolescente que passa por muitas mudanças a escolha também pode significar a perda da identidade infantil. Constitui-se como um período agitado de 
transição, com modificações de suas relações com a família, além das esferas sociais e biológicas (Gondim, Bendassolli, \& Peixoto, 2016). Em meio a essa turbulência, muitos jovens vão enfrentar a transição para o Ensino Superior e precisam optar por uma carreira. Tal escolha transcende a própria pessoa, refletindo-se na família e na sociedade, visto que o trabalho é uma das principais fontes de reconhecimento social da nossa cultura (Ruppanner \& Huffman, 2014). Já para estudantes não tradicionais e com experiências diversas no mercado de trabalho, a escolha profissional muitas vezes diz respeito a um melhor posicionamento no trabalho já exercido, como no caso de promoção, ou mesmo a efetivação de um objetivo de vida não realizado anteriormente devido, por exemplo, a questões financeiras (Costa, Araújo, Gonçalves, \& Almeida, 2013).

A escolha de uma carreira é um momento complexo de tomada de decisão vivenciado. A maturidade psicológica para realização da escolha profissional torna-se um aspecto relevante e está ligada à necessidade de tomar um determinado tipo de decisão, a partir de um conjunto de competências e informações sobre os interesses pessoais de escolha de carreira, acumuladas ao longo do desenvolvimento (Carvalho \& Matos, 2011; Lins, Silva, \& Assis, 2015). Conhecer as características e competências profissionais em muito contribuiria para a maturidade na escolha da carreira.

No caso do curso de Psicologia, as Diretrizes Curriculares Nacionais (Ministério da Educação e Cultura [MEC], 2011) estabelecem que a graduação tem como foco principal a formação do psicólogo voltado para a atuação profissional, para a pesquisa e para o ensino. Dentre os princípios em que se deve basear a formação, estão: a compreensão dos múltiplos referenciais que buscam apreender a amplitude do fenômeno psicológico em suas interfaces com as características biológicas e sociais; o reconhecimento da diversidade de perspectivas necessárias para compreensão do ser humano e o incentivo à interlocução com campos de conhecimento que permitam a apreensão da complexidade e multideterminação desse fenômeno; a compreensão crítica dos elementos sociais, econômicos, culturais e políticos do país, fundamentais ao exercício da cidadania e da profissão, como também a atuação em diferentes contextos, considerando as necessidades sociais e os direitos humanos, tendo em vista a promoção da qualidade de vida dos indivíduos, grupos, organizações e comunidades.

Desta forma, entende-se que a maturidade psicológica para a escolha da carreira aponta para o grau de desenvolvimento afetivo e cognitivo que um indivíduo alcançou para lidar com as tarefas de desenvolvimento vocacional. Como construto, representa um repertório de comportamentos de enfrentamento e aptidões a serem empregados em relação aos eventos relacionados à carreira encontrados em vários estágios de vida (Wicklein \& Schell, 1995). 
Neiva, Silva, Miranda e Esteves (2005), em seus estudos sobre maturidade psicológica para a escolha profissional, construíram um modelo teórico que enfatiza na juventude a aquisição de conhecimentos importantes para a maturidade necessária à decisão profissional. Investigaram o tema admitindo duas dimensões: Atitudes e Conhecimentos. A dimensão Atitudes compõe-se em três subdimensões: determinação para a escolha, que diz respeito a quanto o indivíduo está seguro em relação à escolha profissional; responsabilidade para a escolha profissional, que diz respeito a quanto o indivíduo está envolvido em seu processo de escolha profissional e se dedica em suas ações na tomada de decisão e independência, que fala do quanto o indivíduo de forma autônoma toma sua decisão profissional, sem interferência de outras pessoas como amigos, familiares e professores. A dimensão Conhecimentos é dividida em duas subdimensões: autoconhecimento, que se refere ao conhecimento de si mesmo, suas vivências e experiências pessoais que são importantes para a escolha profissional, como interesses e habilidades e conhecimento da realidade educativa e socioprofissional, que diz respeito ao conhecimento dos jovens sobre as profissões, exigências do mercado de trabalho e instituições educativas.

Outras variáveis podem estar envolvidas na maturidade psicológica para a escolha da carreira, e incluem fatores como: gênero, idade e condições socioeconômicas (Neiva et al., 2005). Patton e Lokan (2001), em revisão de literatura sobre o tema, verificaram que há um aumento da maturidade para a carreira conforme a idade avança. Os autores sugerem que, com relação à idade, associam-se mais os fatores atitudinais do que cognitivos e, com relação ao gênero, a maior parte das pesquisas conduzidas nas últimas duas décadas têm mostrado que as moças apresentam maior maturidade psicológica para a escolha da carreira do que os rapazes.

No contexto brasileiro, há treze anos Neiva et al. (2005) investigaram a maturidade psicológica para a escolha profissional de alunos do Ensino Médio em função do sexo e da escola (pública ou particular). Verificaram que as moças se mostraram mais maduras na escala total, apresentando também maiores índices nas subdimensões responsabilidade e autoconhecimento, e que os alunos de instituição particular mostraram mais maturidade do que os de escola pública. Já Junqueira e Melo-Silva (2014), em pesquisa com 748 estudantes entre 14 e 21 anos de idade, não encontraram diferença significativa entre alunos de escolas públicas e particulares, como também em relação ao sexo. Em ambos os sexos predominou o nível de maturidade total abaixo da média no início do processo, com uma porcentagem próxima entre moças e rapazes. Whiston e Brecheisen (2002) ressaltaram que as diferenças entre os sexos podem estar associadas à idade, sendo esta uma variável mediadora da 
maturidade para a carreira, com homens e mulheres apresentando diferenças maiores durante o Ensino Médio, o que não mais se evidencia na universidade.

A influência da família é muitas vezes determinante na escolha, podendo ou não estar de acordo com os reais desejos e a vocação do adolescente. Schoier, Quadros e Godoy (2015) ressaltam que embora a influência da família não seja diretiva no momento da escolha profissional, é nesse contexto que vão ocorrer negociações objetivas e subjetivas entre os diversos aspectos envolvidos nesse processo. Os autores identificaram que a família é um dos principais fatores que facilitam ou dificultam no momento da escolha e na decisão do jovem, como um elemento de transformação da própria família. No estudo de Santos (2005), que teve como objetivo verificar as percepções dos jovens quanto à influência da família e dos pares na escolha profissional através da análise do discurso de 16 jovens entrevistados, foram levantados indicadores da importância e da influência dos pais no processo de tomada de decisão. Esta pesquisa mostrou que o jovem tende a buscar o primeiro apoio na família na hora em que precisa escolher uma profissão.

De acordo com a pesquisa realizada por Mourão e Abbad (2016), o perfil do estudante de Psicologia no Brasil apresenta como prevalência o público feminino, com concentração de idade de até 30 anos, e muitos estudantes trabalham fora da área de Psicologia durante o curso. Em relação à escolha pelo curso de Psicologia, Carvalho e Matos (2011) encontraram diversidade de aspectos, ora focados na profissão, ora na pessoa do estudante de Psicologia. Identificaram como fontes determinantes para a maturidade psicológica na escolha profissional: experiências promotoras de reflexão e questionamentos no contexto de pares e de familiares; acontecimentos que desencadearam crises pessoais, tais como rupturas relacionais e perdas subjacentes ao interesse pelas motivações e compreensão do comportamento humano; impacto de experiências dramáticas e dificuldades sentidas, em especial no âmbito conjugal e familiar, vendo na prática da profissão a capacidade de devolver esperança. Pode-se verificar, dessa forma, uma interseção entre o que a profissão pelas suas características permite vivenciar e o que os estudantes necessitam pela sua personalidade.

Bastos e Gomide (2010) propuseram três grandes blocos de aspectos apontados pelos entrevistados para a escolha pela graduação em Psicologia: razões pessoais (motivos voltados para si, a exemplo do autoconhecimento e crescimento pessoal ou solução de problemas); razões humanísticas (motivos voltados para o outro, tais como conhecer ou ajudar o ser humano) e razões voltadas para a profissão, não necessariamente para o exercício da mesma, mas por um interesse genérico pela Psicologia enquanto área de conhecimento. 
Há, ainda, na pesquisa, citações de aspectos sem nenhuma relação com a profissão como sendo segunda opção ou a proximidade da faculdade. Dos aspectos elencados os de "razões pessoais" apresentaram peso elevado.

Em estudo com 63 estudantes entre 15 e 19 anos de idade, MeloSilva, Oliveira e Coelho (2002) realizaram intervenção para avaliar a influência da orientação profissional na maturidade psicológica para a escolha da carreira. Como instrumento de pré e pós testes, foi utilizada a Escala de Maturidade para a Escolha Profissional (EMEP). Os resultados do total da amostra demostraram diferença significativa nas dimensões: Determinação, Autoconhecimento, Conhecimento da Realidade, Independência e no Total das subescalas, indicando avanço na maturidade para a escolha da carreira.

Em linhas gerais a adequação da escolha da profissão está ligada a fatores psicológicos, familiares, sociais, educacionais e econômicos (Gondim et al., 2016). Esse momento de decisão influenciado por tantas variáveis é, portanto, cercado por ansiedade e estresse e exige certo grau de maturidade por parte dos estudantes. Tendo em vista a multiplicidade de fatores envolvidos na maturidade psicológica para a escolha da carreira, o presente estudo teve como objetivo identificar as concepções de maturidade psicológica para a escolha da graduação em Psicologia. O objetivo deste estudo pode apontar caminhos para formulação de ferramentas, como intervenções e orientação profissional que contribuam na formação dos futuros profissionais.

\section{Método}

O presente estudo é qualitativo, o que proporciona um conhecimento mais profundo e subjetivo do indivíduo ou grupo pesquisado (Dias, 2000), de natureza transversal e exploratório, e utilizou a metodologia de Grupo Focal. Segundo Ressel et al. (2008), os grupos focais discutem um tema específico, sendo os participantes estimulados para tal. É na integração grupal que é possível a coleta de dados. O objetivo geral do grupo focal é identificar percepções, afetos, comportamentos, provocar novas ideias e opiniões dos participantes a respeito de um determinado assunto. Em termos de objetivos específicos, surgem de acordo com a abordagem da pesquisa. Nas pesquisas exploratórias, como o presente estudo, 0 propósito é provocar novas ideias ou hipóteses. 


\subsection{Participantes}

Participaram 13 estudantes de graduação em Psicologia de uma instituição particular de Ensino Superior escolhida por conveniência, de ambos os sexos e com idades entre 20 e 48 anos ( $M=32,15 \%$; DP $=9,54)$. Em termos de estratos socioeconômico, três $(23,1 \%)$ estudantes pertenciam à classe social $\mathrm{A}$, dois à $\mathrm{B} 1$, um à $\mathrm{B} 2$, quatro à $\mathrm{C} 1$ e dois à C2 segundo ABEP (2016). Os períodos letivos foram um participante do primeiro, três do segundo, um do terceiro e quinto respectivamente, três do sexto, um do sétimo e dois do oitavo.

\subsection{Procedimentos de coleta de dados}

Os participantes receberam convite individual e foram previamente informados sobre a atividade, o local e a data. Das turmas convidadas, compareceram 13 voluntários. Segundo Dias (2000), o grupo focal reúne de seis a 10 pessoas e considera as características das mesmas e a discussão proposta. Segundo a autora, o número de seis pessoas possibilita o surgimento de ideias e opiniões, e um número maior de 10 participantes já dificulta o gerenciamento, considerando o foco da discussão e o tempo para a participação de todos.

Inicialmente, disponibilizou-se um lanche para acolhimento dos estudantes e também para evitar deslocamentos durante a realização da atividade que pudessem interferir em seu desenvolvimento. $O$ grupo focal ocorreu em uma sala que acomodou adequadamente todos os participantes. Os discentes responderam in loco 0 Questionário Sociodemográfico. Todas as pessoas receberam crachá de identificação e o moderador apresentou os objetivos do trabalho. O grupo focal foi conduzido pelo moderador, que estabeleceu as regras de conduta, ressaltando a importância da fala de todos do grupo e que não haveria posicionamentos considerados certos ou errados. O observador ressaltou ainda o caráter sigiloso dos dados dos participantes, das questões discutidas no grupo, sendo reforçado que não houvesse comentários externos sobre as discussões do grupo. Para facilitar o início da atividade, foram introduzidos "motes" que funcionaram como norteadores da discussão, versando sobre o conceito proposto: $O$ que vocês acham sobre a escolha profissional?; Como foi a tomada de decisão?, Houve influência de outras pessoas na decisão?; Vocês conheciam a profissão propriamente dita? Conheciam a inserção no mercado de trabalho? As falas foram gravadas. O grupo focal teve duração de uma hora e trinta minutos. 


\subsection{Procedimentos Éticos}

Os discentes foram informados sobre o objetivo do estudo, da participação voluntária e não remunerada, que poderiam se retirar da pesquisa em qualquer momento e todos assinaram o Termo de Consentimento Livre e Esclarecido (TCLE). A pesquisa foi aprovada pelo Comitê de Ética em Pesquisa da Universidade.

\subsection{Procedimentos de Análise dos Dados}

As falas foram transcritas, respeitando a forma de expressão de cada participante, e inseridas como corpus textual no programa utilizado para a análise dos dados. Utilizou-se o software Iramuteq 0.7 (Camargo, 2013). Segundo o autor, o programa possibilita a otimização do processo de organização e delimitação mais específica das falas dos participantes, o que propicia o levantamento de aspectos lexicais esquematizados. Ressalta-se que o programa Iramuteq lida com unidades de contexto iniciais ( $\mathrm{UCls}$ ) que podem ser estruturadas de diferentes maneiras dependendo dos dados coletados. Ao se trabalhar falas de participantes, cada fala compôs uma $\mathrm{UCl}$. O conjunto de $\mathrm{UCls}$ froma o corpus de análise que $\mathrm{o}$ programa divide em segmentos de textos, os quais são as unidades de contexto elementar (UCEs). Em seguida, o software realiza uma classificação hierárquica descendente (CHD), formando as classes lexicais constituídas pelo vocabulário e por segmentos de texto. Por fim, o autor afirma que as classes que são extraídas do corpus do texto representam o sentido das palavras utilizadas e que podem sugerir constituintes pertencentes, no caso do presente estudo, à concepção de maturidade psicológica para escolha profissional.

Neste sentido, as contribuições dos participantes foram organizadas em um único corpus e analisadas por uma CHD. A análise visa obter classes de Segmento de Texto (ST), indicando as semelhanças e diferenças no vocabulário dos ST das classes (Castro, Koelzer, Camargo, \& Bousfield, 2014). Os autores esclarecem ainda que o CHD oferece análise do vocabulário textual, os ST são organizados conforme a frequência das palavras, o que gera classes de sentido dos vocábulos.

\section{Resultados}

A Classificação Hierárquica Descendente (CHD) reteve $81,56 \%$ da totalidade dos textos e obteve-se duas classes centrais, conforme a Figura 1, sobre a significação dos alunos quanto as percepções de maturidade psicológica para escolha do curso de Psicologia. 


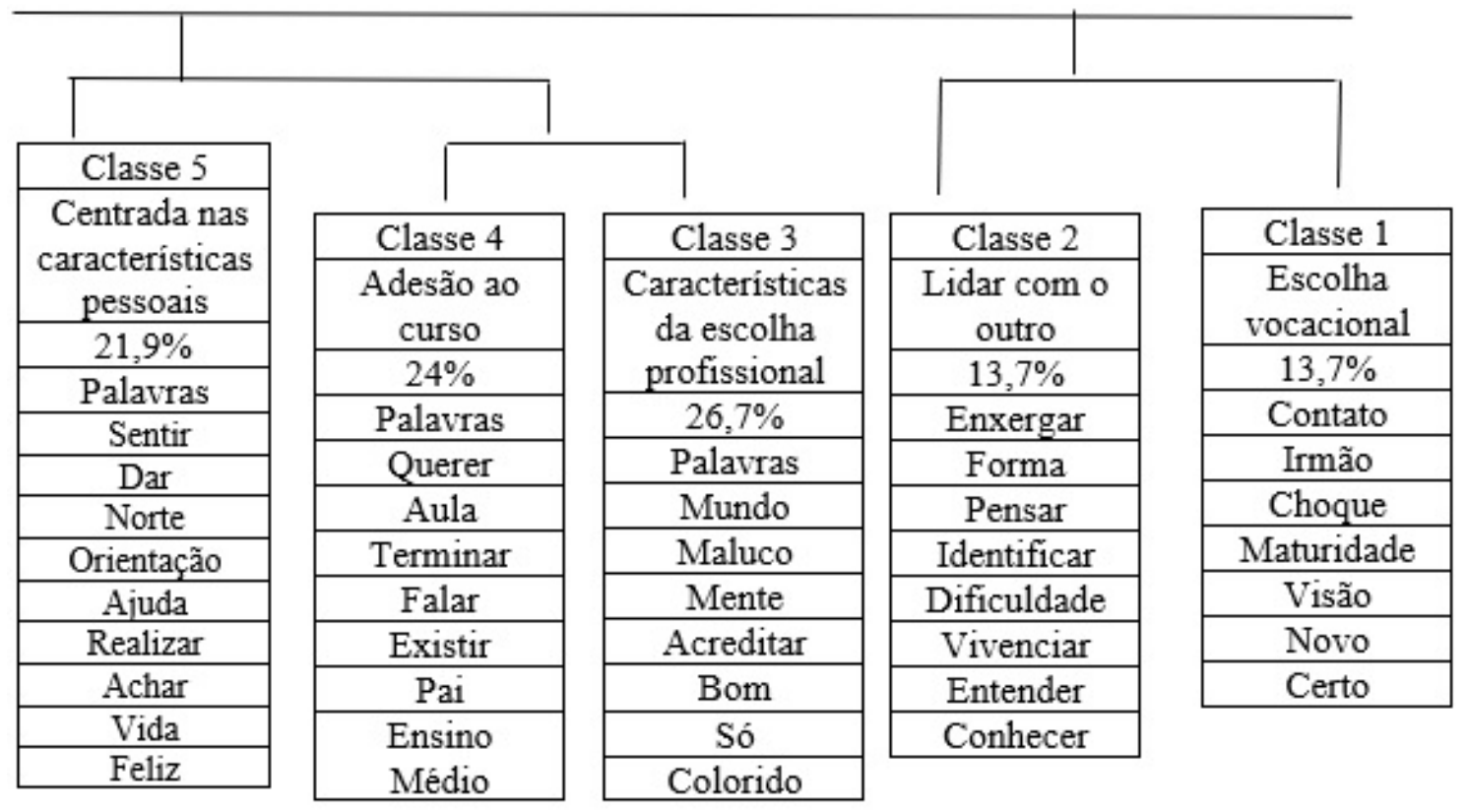

Figura 1 - Dendograma da CHD

A Figura 1 apresenta as classes obtidas na análise. A Classe Central denominada Conhecimento para a escuta do outro foi desmembrada em duas classes: Escolha vocacional (Classe 1 ) com $13,7 \%$ de comentários; aponta aspectos considerados relevantes para a maturidade psicológica na escolha do curso relacionados com experiências pessoais com as dificuldades do outro ou de si. Os elementos que compõem esta classe mostram a busca da compreensão com a dinâmica do psiquismo, exemplificado no comentário "No meu caso a escolha para Psicologia foi um caso particular. Na verdade, o meu irmão é esquizofrênico e aquilo me tocou muito, me incomodou muito" (participante 5) e "Gostei de fazer Psicologia, era um sonho meu, e na minha adolescência eu passei por uns problemas, mais emocionais. Assim, eu fazia terapia, então eu via como era tão bom" (participante 12). Outra classe foi denominada de Lidar com o outro (Classe 2) que também apresentou 13,7\% dos comentários, mostrando que a concepção de maturidade psicológica para a escolha do curso de Psicologia está relacionada à representação do outro nas singularidades por meio de processo de escuta diferenciada compreendida como ferramenta essencial do psicólogo. O processo de escuta não é aleatório, mas obtido por conhecimento durante a graduação. "Você pode dar uma orientação, você pode parar para ouvir e você direciona a pessoa" (participante 9) e "Busca ao conhecimento do outro. Assim a curiosidade de entender, de conhecer mais." (participante 3). A maturidade para a escolha do curso de Psicologia envolve o investimento em conhecimento para aprender sobre as diferenças. 
A segunda Classe Geral Escolha para perceber a si e ao outro foi dividida em duas Classes Centrais. A primeira, denominada de Centrada nas características pessoais (Classe 5), apresentou $21,9 \%$ de componentes, que envolveram as concepções de perceber o outro, de saber orientar, ajudar e considerar a realidade de si e do outro. Sendo exemplificada em "Quando assim alguém tá passando por um sofrimento, não é que eu me alegre com o sofrimento das pessoas, mas eu gosto de tá ali, junto ali, para poder ajudar, entendeu? Então, eu amo assim muito lidar com pessoas e ajudar pessoas." (participante 4). Reconhecer em si e na profissão qualidades ou habilidades que sejam primordiais para abraçar a profissão de psicólogo parece ser determinante para os alunos se perceberem maduros na sua escolha.

Outra Classe Central foi denominada de Concepções de ser psicólogo, que foi desmembrada em duas: Adesão ao curso (Classe 4) e Características da Escolha Profissional (Classe 3). A primeira foi composta por $24 \%$ dos comentários e ressalta a firmeza em fazer a opção pelo curso, mesmo que diante de situações adversas. Há o comprometimento e empenho com a graduação e a real intenção de concluí-la, tornando-se psicólogo: "Não, não vou fazer o que meu pai quer, vou fazer o que eu quero! Vou mergulhar" (participante 13). "Fiz alguns cursos, fiz outra faculdade. Aí larguei e comecei Psicologia" (participante, 7).

A segunda foi Características da escolha profissional e recebeu a maior porcentagem de comentários $(26,7 \%)$ (Classe 3 ). Esta indica as concepções vinculadas ao ser psicólogo, trazendo, inclusive estereótipos refletidos na escolha da profissão: “Então, qualquer coisa que eu dizia de uma metáfora, sempre era visto como um maluco" (participante 10) e em "Ele falava (meu pai) que Psicologia era coisa de patricinha" (participante 7). As concepções sobre maturidade foram apontadas nas Classes obtidas pela análise dos dados. As Classes traduzem o discurso dos estudantes sobre as características que estes compreendem o que é ser psicólogo. Os participantes entendem que ser psicólogo é aquele profissional que ao buscar o curso precisa ter a maturidade de saber que irá lidar com características muito peculiares do comportamento individual e social e se dedicará ao estudo do funcionamento do psiquismo.

\section{Discussão}

Os resultados indicam que a concepção de maturidade psicológica para a escolha do curso de Psicologia tem relação com as características ou habilidades percebidas pelos alunos, e deverá ser desenvolvida ao longo da graduação. A Classe Lidar com o outro está vinculada a uma escuta própria do profissional de psicologia, que tem 
no conhecimento adquirido na graduação o seu suporte. Mais especificamente, corresponderia ao conhecimento da realidade educativa e socioprofissional, o que supostamente é compreendido pelos participantes como elemento fundamental para entender os processos psicológicos. Entretanto, Mourão e Abbad (2016) ressaltam o pouco envolvimento acadêmico do estudante durante a graduação. Para os autores, este comportamento reflete que o aluno ainda não está sensível ou motivado para apropriar-se do compromisso que envolve a futura carreira. Muitos estudantes que vêm acessando os cursos de Ensino Superior trazem uma diversidade de experiências pedagógicas e organização para o estudo que nem sempre garantem que ao discente competências que facilitem 0 processo de aprendizagem.

Apesar de externalizarem que adquirir conhecimento durante a formação está relacionado a uma prática eficiente, Mourão e Abbad (2016) sinalizam que há déficit entre a relação entre teoria e prática apresentada pelos graduandos. As autoras ressaltam que o aluno não demonstra a autonomia ou responsabilidade em buscar, durante a sua formação, uma diversificação de saberes integrados com outras áreas do conhecimento, necessários para a compreensão do dinamismo do sujeito e da interação com fenômenos sociais e econômicos no intuito de abraçar e defender os direitos da pessoa.

Neste sentido, Rocha, Silva, Barbosa \& Duarte (2013) ressaltam que a relação entre teoria e prática deve ser a tônica da graduação. Para os autores, o desenvolvimento de conteúdos teóricos deve ser proposto por meio de práticas reais ou simulações que retratem a vida profissional, visando contemplar a conexão entre teoria e prática. Tal conexão implica em processos didáticos diversificados, 0 que também exige dos docentes repensarem a prática e as dificuldades decorrentes do processo de ensino, o que também demanda um investimento institucional no professor para que este alinhe teoria e prática com eficiência. Ademais, as técnicas devem ser relacionadas aos conhecimentos conceituais, evitando-se a aceitação passiva de conteúdos teóricos e a repetição de modus operandis. O aluno ao longo da graduação deveria adquirir um conjunto de competências e que articuladas com vivências práticas supostamente contribuiria para consolidar a maturidade psicológica na decisão da escolha do curso.

Ainda que a literatura aponte déficits na formação dos estudantes de psicologia, a busca pela graduação, refletida em números nos vestibulares mais concorridos do país, pode retratar 0 desconhecimento da relação entre teoria e prática, além do desenvolvimento de competências. O processo seletivo da Fuvest 2016, um dos mais disputados no setor da educação pública, a relação candidato/vaga foi de 59,80 ficando atrás apenas de Medicina de Ribeirão Preto $(71,93)$ e superando Medicina de São Paulo $(58,75)$ 
(Guia do Estudante, 2017). Na Unesp o número de candidatos passou de 3 mil para 4 mil entre 2012 e 2016, sendo o terceiro curso superior mais buscado no primeiro semestre de 2016, atrás novamente o de Medicina e o de Direito (Guia do Estudante, 2017).

Já a Classe Escolha vocacional aponta o interesse de ser um profissional que, tendo vivenciado situações de dificuldades pessoais, percebe-se com o desejo de compreender profundamente o outro a fim de poder ajudá-lo a superar problemas sentimentais e existenciais por meio de habilidades de escuta, de equilíbrio, tranquilidade, reflexão, tolerância e interesse pelo indivíduo. 0 estudante, ao abraçar o curso, entende que possui as referidas habilidades a serem aperfeiçoadas na universidade, associadas às experiências de situações anteriores, que contribuíram com a recorrente concepção de que a ajuda profissional encontrada no passado é a ajuda que pretende proporcionar ao outro (Carvalho \& Matos, 2011). Entretanto, as exigências atuais no mundo do trabalho têm orientado discussões sobre o papel das universidades na formação humana, social, cultural e profissional, pontuando a imprescindibilidade do desenvolvimento de competências técnicas e interpessoais que possam ser articuladas com o cenário social, o que gera mudanças curriculares no Ensino Superior (Gondim et al., 2016), como também do papel do aluno neste contexto.

A Classe Características da escolha profissional remete a preconcepções de que para ser psicólogo tem-se um talento para gerir distúrbios comportamentais ou mesmo a vocação sacerdotal de ajudar o outro sem preocupação com proventos. Entretanto, alguns dados trazidos por Yamamoto, Falcão e Seixas (2011) mostram uma situação que se apresenta bem distinta. Para os autores, a graduação em psicologia insere-se nos cursos que figuram na denominação de elite, e são caracterizados pela seletividade nas taxas de concorrência dos exames de vestibulares, na condição socioeconômica dos alunos e no status social conferido ao curso. Ademais, a caraterização das graduações acaba por compor dois grupos distintos: os elitizados, constituídos por jovens advindos de famílias com tradição no Ensino Superior e nível socioeconômico entre 10 a 30 salários mínimos e com acesso às instituições públicas, cujo processo seletivo é mais criterioso; e os não-elitizados, sem tradição escolar na educação superior, de faixa salarial até cinco salários mínimos e com acesso às instituições privadas, que apresentam um ingresso menos seletivo. Os dois grupos constituídos reforçam a concepção de que os nãoelitizados ocupam prioritariamente as vagas nas IES privadas e oS elitizados o sistema público (Yamamoto et al., 2011). Os autores ressaltam, ainda, que a graduação de Psicologia tem no seu contexto estudantes com antecedentes culturais e socioeconômicos no grupo parcialmente seleto.

As poucas alusões às aspirações financeiras podem ainda representar 
a relativa despreocupação com este aspecto, em contraste às motivações intrínsecas para obter resultados de uma relação de construção positiva de ajuda ao outro. Segundo Magalhães, Straliotto, Keller e Gomes (2001) parece que é priorizado o aspecto interpessoal da atividade profissional em detrimento de recompensas externas. O futuro profissional se mobiliza mais pelo prazer de ser psicólogo, pelas possibilidades de autoconhecimento, de conhecimento, ajuda e contato com o outro do que pelas condições em que o trabalho da psicologia é exercido (Magalhães et al., 2001).

A Classe Adesão ao curso possui estreita associação com o esforço e empenho em concluir a graduação almejada. Junqueira e Melo-Silva (2014) salientam que a maturidade psicológica para a escolha profissional se reporta a uma prontidão para lidar com competências relacionadas à escolha da carreira, que irá exigir do estudante tomada de decisão consciente e autônoma. A integração ao curso exige envolvimento social e integração acadêmica do aluno não apenas nos períodos iniciais da graduação, mas ao longo de todo o curso. Supostamente, são discentes que apresentam um autoconhecimento de si acentuado e que não se abatem diante dos obstáculos e exibem recursos internos o suficiente para investirem em estratégias adequadas diante das dificuldades, além de terem conhecimento da realidade educacional e socioprofissional da carreira que ambicionam (Junqueira \& Melo-Silva, 2014). Esta subclasse abrange duas subdimensões da dimensão atitudinal do modelo de Neiva et al. (2005), mais especificamente a segurança em relação à escolha profissional e a responsabilidade na escolha.

A escolha profissional compreende aspectos sociais, afetivos e pessoais e, no caso da psicologia, a vontade de ajudar o outro parece ser de destaque na concepção dos estudantes quanto à prática profissional. A Classe Centrada nas características pessoais parece associar-se a esse desejo de ajuda, o que, em princípio, incluiria muito mais fatores internos do que externos na escolha do curso (Lins et al., 2015). Os autores destacam que é pertinente afirmar que motivos como o desenvolvimento pessoal, as habilidades interpessoais, e a vontade de compreender a subjetividade também se fazem presentes e levam à graduação de psicologia. Neste sentido, os diferentes motivos que conduzem à escolha do curso (Carvalho \& Matos, 2011) acontecem a partir do momento em que o estudante acredita ser detentor de atributos fundamentais para o exercício da profissão. Para ser psicólogo, dentre as características pessoais necessárias, é preciso haver determinação e segurança na escolha. Ambas, a determinação e a segurança, apresentariam relação com comportamentos esperados do profissional em psicologia.

Mourão e Abbad (2016) ressaltam que as competências para ser psicólogo são complexas, pois abrangem aspectos cognitivos, atitudinais; conhecimentos filosóficos, epistemológicos, éticos e 
metodológicos; habilidades de trabalhar em equipe e avaliações contextuais. Competências que parecem ser desconhecidas daqueles que escolhem o curso respaldados muitas vezes em experiências pessoais ou na crença de possuírem as habilidades exigidas para o pleno exercício da profissão de psicólogo. O autoconhecimento (Neiva et al., 2005) parece ser a tônica que muito facilitaria a tomada de decisão pelo curso.

O presente estudo apontou que estudantes que decidem pela graduação em psicologia concebem a percepção de maturidade psicológica para a escolha do curso implica em habilidades de empatia ao saber escutar e lidar com o sofrimento do outro; de investigação, no intuito de adquirir conhecimento e a prática para cuidar do outro e de relacionamento, sendo capaz de conduzir vínculos com perspicácia (Gondim et al., 2016). Diferentemente de estudo conduzido por Neiva et al. (2005) com estudantes do Ensino Médio, que ressaltou características sociodemográficas de gênero, idade e nível socioeconômico na maturidade psicológica para a escolha profissional.

Por fim, os dados coletados a partir do grupo focal realizado com estudantes e posterior análise dos dados permitiu a extração de cinco classes que corroboram com estudos propostos na área (Junqueira \& Melo-Silva, 2014; Neiva et al., 2005). já que a dimensão atitudinal corresponderia às classes 4 e 5 aqui apresentadas. Mais precisamente, a determinação da escolha e a segurança na escolha se encontrariam nas Classes 4 e 5 . Por sua vez, a responsabilidade na escolha se encontraria parcialmente contemplada na Classe 4. A dimensão de conhecimento se refletiria na Classe 1 (autoconhecimento) e na Classe 2 (conhecimento da realidade educativa e socioprofissional). A Classe 3, que trata das características da escolha com as preconcepções acerca do trabalho do psicólogo, não foi contemplada pelo modelo de Neiva e colaboradores (2005).

\section{Considerações Finais}

O estudo teve como objetivo identificar as concepções de maturidade psicológica para a escolha da profissão, especificamente para os estudantes de Psicologia. Os resultados apontaram para cinco classes gerais: Escolha vocacional; Lidar com o outro; Características da escolha profissional; Adesão ao curso e Centrada nas características pessoais. A pesquisa mostrou que a concepção para a escolha do curso de Psicologia tem relação com as características ou habilidades percebidas pelos alunos e deverão ser desenvolvidas ao longo de sua formação. Estudos apontam que há déficits teóricos e práticos na formação dos psicólogos e, portanto, compreender as percepções de 
maturidade psicológica dos estudantes para a escolha do curso de Psicologia pode contribuir para uma melhora na formação desses profissionais, fornecendo dados às universidades para reestruturação de abordagens e suporte aos estudantes que favoreçam um melhor desenvolvimento profissional e pessoal. $O$ estudo também colabora para ampliar o entendimento do perfil do Psicólogo no Brasil, uma vez que busca elucidar as concepções de maturidade psicológica para escolha profissional dos alunos que optaram por esta carreira.

Em relação às limitações desse trabalho, pode ser destacado o fato da reduzida amostra dos participantes, envolvendo apenas uma universidade particular e também o fato do estudo ter sido realizado apenas no Estado do Rio de Janeiro (restrição peculiar da cultura regional), sendo sugeridos estudos com amostras de universitários da rede pública e de outras regiões do país a título de comparação.

\section{Referências}

Associação Brasileira de Empresas de Pesquisa (2015). Critério Brasil. São Paulo: ABEP. Recuperado de http://www.abep.org/criteriobrasil

Bastos, A. V. B., \& Gomide, P. I. C. (Orgs.). (2010). O Trabalho do Psicólogo no Brasil. Porto Alegre: Artmed.

Brasil. Ministério da Educação [MEC]. (2011). Diretrizes Curriculares Nacionais para os cursos de graduação em Psicologia. Brasília, DF: MEC. Recuperado de http://portal.mec.gov.br/maiseducacao/323-secretarias-112877938/orgaos-vinculados-

$82187207 / 12991$-diretrizes-curriculares-cursos-degraduacao\% 20em $\% 2010 \% 20$ de $\% 20$ agosto $\% 20$ de $\% 202017$

Camargo, B. V., \& Justo, A. M. (2013). IRAMUTEQ: Um software gratuito para análise de dados textuais. Temas em Psicologia, 21(2), 513-518. doi: 10.9788/TP2013.2-16

Carvalho, H., \& Matos, P. (2011). Ser e tornar-se Psicoterapeuta parte 1: diálogo entre experiências pessoais e profissionais. Psicologia: Ciência e Profissão, 31(1), 80-95. doi: 10.1590/S1414-98932011000100008

Castro, A., Koelzer, L. P., Camargo, B. V., \& Bousfield, A. B. S. (2014). Representações sociais na internet sobre cotas para negros em universidades federais. Cadernos de Pesquisa Interdisciplinares em Ciências Humanas, 15(106), 202-220. doi: 10.5007/1984-8951.2014v15n106p202

Costa, A. R., Araújo, A. M., Gonçalves, P., \& Almeida, L. (2013). Expectativas académicas em alunos tradicionais e nãotradicionais de engenharia. Revista Peruana de Psicología y Trabajo Social, 2(1), 63-74. 
Dias, C. A. (2000). Grupo focal: técnica de coleta de dados em pesquisas qualitativas. Informação \& Sociedade: Estudos, 10(2), 1-12.

Gondim, S. M. G., Bendassolli, P., \& Peixoto L. S. A. (2016). A Construção da Identidade Profissional na Transição Universidade-Mercado de Trabalho. In A. B. Soares, L. Mourão, M. M. P. E. Mota (Orgs.), O Estudante Universitário Brasileiro: Características Cognitivas, Habilidades Relacionais e Transição para o Mercado de Trabalho (pp. 219-234). Curitiba: Appris Editora.

Guia do Estudante (2017). Psicologia. Recuperado de https://guiadoestudante.abril.com.br/profissoes/psicologia/

Junqueira, M. L., \& Melo-Silva, L. L. (2014). Maturidade para a escolha de carreira: estudo com adolescentes de um serviçoescola. Revista Brasileira de Orientação Profissional, 15(2), 187-199.

Lins, L. F. T., Silva, L. G., \& Assis, C. L. (2015). Formação em Psicologia: perfil e expectativas de concluintes do interior do Estado de Rondônia. Gerais: Revista Interinstitucional de Psicologia, 8(1), 49-62.

Magalhães, M. O., Straliotto, M., Keller, M., \& Gomes, W. B. (2001). Eu quero ajudar as pessoas: A escolha vocacional da psicologia. Psicologia Ciência e Profissão, 21(2), 10-27. doi: 10.1590/S1414-98932001000200003

Melo-Silva, L. L., Oliveira, J. C. D., \& Coelho, R. D. S. (2002). Avaliação da orientação profissional no desenvolvimento da maturidade na escolha da profissão. Psicologia, 3(2), 44-53.

Mourão, L. \& Abbad, G. S. (2016). As lacunas de competências na formação em Psicologia e os riscos para a atuação na área profissional. In A. B. Soares, L. Mourão, \& M. M. P. E. Mota (Orgs.), O Estudante Universitário Brasileiro: Características Cognitivas, Habilidades Relacionais e Transição para o Mercado de Trabalho (pp. 219-234). Curitiba: Appris Editora.

Neiva, K. M. C., Silva, M. B., Miranda, V. R., \& Esteves, C. (2005). Um estudo sobre a maturidade para a escolha profissional de alunos do ensino médio. Revista Brasileira de Orientacão Profissional, 6(1), 1-14.

Patton, W., \& Lokan, J. (2001). Perspectives on Donald Super's construct of career maturity. International Journal for Educational and Vocational Guidance, 1(1), 31-48.

Ressel, L. B., Beck, C. L. C., Gualda, D. M. R, Hoffmann, I. C., da Silva, R. M., \& Sehnem, G. D. (2008). O uso do grupo focal em pesquisa qualitativa. Texto \& Contexto - Enfermagem, 17(4), 779-786. doi: 10.1590/S0104-07072008000400021

Rocha, A. C., Silva, G., Barbosa, R., \& Duarte, C. (2013). Tornar-se Psicólogo para além das aulas: Grupo de desenvolvimento com 
estudantes de Psicologia. Análise Psicológica, 31(1), 87-102. Recuperado de http://www.scielo.mec.pt/scielo.php?script=sci_arttext\&pid=S0 870-82312013000100006

Ruppanner, L., \& Huffman, M. L. (2014). Blurred boundaries: Gender and work-family interference in cross-national context. Work and Occupations, 210-236. doi: $10.1177 / 0730888413500679$.

Santos, L. M. M. (2005). O papel da família e dos pares na escolha profissional. Psicologia em Estudo, 10(1), 57-66. Recuperado de http://www.scielo.br/pdf/pe/v10n1/v10n1a07.pdf

Schoier, B. J., Quadros, B., Godoy, L. P., \& Pacheco, S. B. (2015, Novembro 29). Influência familiar na escolha da graduação. Psicologia.pt: o portal dos psicólogos. Recuperado de http://www. psicologia.pt/artigos/textos/A0936.pdf

Whiston, S. C., \& Brecheisen, B. K. (2002). Evaluating the effectiveness of adult career development programs. In S. G. Niles (Ed.), Adult career development: Concepts, issues, and practices (pp. 367-384). Tulsa, OK: National Career Development Association.

Wicklein, R. C., \& Schell, J. W. (1995). Case studies of multidisciplinary approaches to integrating mathematics, science, \& technology education. Journal of Technology Education, 6(2), 1-6.

Yamamoto, O. H., Da Rocha Falcão, J. T., \& Seixas, P. S. (2011). Quem é o estudante de Psicologia do Brasil? Avaliação Psicológica, 10(3), 209-232. Recuperado de http://pepsic. bvsalud.org/scielo.php?script=sci_arttext\&pid=S1 677-04712011000300002

\section{Endereço para correspondência \\ Adriana Benevides Soares}

Universidade Salgado de Oliveira - UNIVERSO

R. Mal. Deodoro, 217, Bloco A, Centro, CEP 24030-060, Niterói - RJ, Brasil

Endereço eletrônico: adribenevides@gmail.com

\section{Marisangela Siqueira de Souza}

Universidade Salgado de Oliveira - UNIVERSO

R. Mal. Deodoro, 217, Bloco A, Centro, CEP 24030-060, Niterói - RJ, Brasil

Endereço eletrônico: profmarisangela@gmail.com

\section{Marcia Cristina Monteiro}

Universidade Salgado de Oliveira - UNIVERSO

R. Mal. Deodoro, 217, Bloco A, Centro, CEP 24030-060, Niterói - RJ, Brasil

Endereço eletrônico: marcialauriapsi@outlook.com

\section{Rafael Moura Coelho Pecly Wolter}

Universidade Federal do Espírito Santo - UFES

Programa de Pós-Graduação em Psicologia

Av. Fernando Ferrari, 514, Goiabeiras, CEP 29075-910, Vitória - ES, Brasil

Endereço eletrônico: rafaelpeclywolter@gmail.com 
Adriana Benevides Soares, Marisangela Siqueira de Souza, Marcia Cristina Monteiro, Rafael Moura Coelho Pecly Wolter

Recebido em: 10/09/2018

Reformulado em: 02/01/2019

Aceito em: 09/01/2019

\section{Notas}

* Psicóloga, Professora Titular do Programa de Pós-graduação em Psicologia (Mestrado e Doutorado) - Universidade Salgado de Oliveira - UNIVERSO - Niterói Brasil, Professora Associada do Departamento de Fundamentos da Psicologia Universidade do Estado do Rio de Janeiro - UERJ - RJ - Brasil, Bolsista de Produtividade CNPq, Cientista do Nosso Estado - FAPERJ .

** Educadora pela Universidade Federal do Rio de Janeiro - UFRJ, Mestre em Psicologia Social pela Universidade Salgado de Oliveira - UNIVERSO, Niterói Brasil, Docente na Secretaria Municipal de Educação do Rio de Janeiro - SME RJ.

*** Psicóloga, Doutora em Psicologia Social pela Universidade Salgado de Oliveira - UNIVERSO, Niterói - Brasil; Mestre em Psicologia Social pela Universidade Federal do Rio de Janeiro-UFRJ; realiza estágio pós-doutoral na Universidade Salgado de Oliveira - UNIVERSO, Niterói. Docente na União das Instituições Educacionais do Estado de São Paulo - UNIESP, Duque de Caxias - Brasil.

**** Psicólogo, Docente no Programa de Pós graduação em Psicologia (Mestrado e Doutorado) - Universidade Federal do Espírito Santo - UFES - ES - Brasil.

Financiamento: CNPq, FAPERJ .

Este artigo de revista Estudos e Pesquisas em Psicologia é licenciado sob uma Licença Creative Commons Atribuição-Não Comercial 3.0 Não Adaptada. 